\title{
Observations on Sphaleromantis tetragona
}

\author{
BY KATHARINE HARRIS \\ Botany Department, University of Reading
}

(Received 15 July 1963)

\begin{abstract}
SUMMARY
Sphaleromantis tetragona Skuja, which has not been previously reported for Britain, is described with the use of the optical and the electron microscopes. The organism possesses an elaborate sheath which is not visible with the optical microscope; the sheath is probably made of organic material. Cell division and cyst formation are described. The cyst, not previously known, is described as seen with the optical microscope.
\end{abstract}

\section{METHODS}

The methods used for making preparations for the electron microscope were nearly the same as those described by Harris \& Bradley (1958) but differed in some details. A drop taken from a concentrated suspension of living organisms was placed on a microscope slide, fixed by exposure to osmic acid vapour for $30 \mathrm{sec}$. and dried. A carbon film about $200 \mathrm{~A}$ thick was deposited on the dry residue and this preparation was mounted on copper grids for use in the electron microscope. The process of backing the film with plastic, previously used, was omitted. These grids were used without further treatment in making the direct micrographs. For the replicas the removal of the cell contents was necessary, but since the sheath is not made of silica no treatment with hydrofluoric acid was required. Equal weights of potassium permanganate and potassium dichromate were mixed and finely powdered; about $0.02 \mathrm{~g}$. of this powder was mixed with about $0.2 \mathrm{ml}$. concentrated sulphuric acid and stirred until a dark green liquid was produced (chromic + sulphuric acid mixture used by D. E. Bradley in the procedure for making carbon replicas). The grids were floated one by one on a small quantity of this liquid and then washed in distilled water. I put one drop of the chromic + sulphuric acid mixture on a slide, floated the grid on this for $2 \mathrm{~min}$., by which time it had begun to sink, removed the grid, dried it slightly on filter paper and transferred it to a drop of distilled water. I repeated this washing twice more and put the grid aside to dry.

\section{OBSERVATIONS}

Occurrence. Sphaleromantis tetragona was found on February 1962 in a small pond by the roadside at Arborfield Cross, Berkshire (National Grid 470,076 E., $160,067 \mathrm{~N}$.). It was very numerous, very few other organisms were present in the water and it was therefore particularly suitable for study with the electron microscope. Cysts were found in large numbers on 28 February 1962. During 1963, up to the end of April, it has been seen three times, but each time in small numbers only and in a mixed flora. 
Light microscopy. In its typical vegetative condition Sphaleromantis tetragona is a small flattened organism appearing square, oblong or trapezoid, with a depression in its anterior end and often also in its posterior end. The single flagellum is situated at the side of the anterior depression. No enclosing sheath is visible when the organism (living or fixed) is mounted in water. Cytological details, including the nucleus and contractile vacuoles, were not studied, but the chromatophore was examined in living and in osmic acid-fixed material. The chromatophore is $U$ shaped, one arm being broader and paler than the other; the narrow arm possesses the red eye spot or stigma (Fig. 1; 1-3).

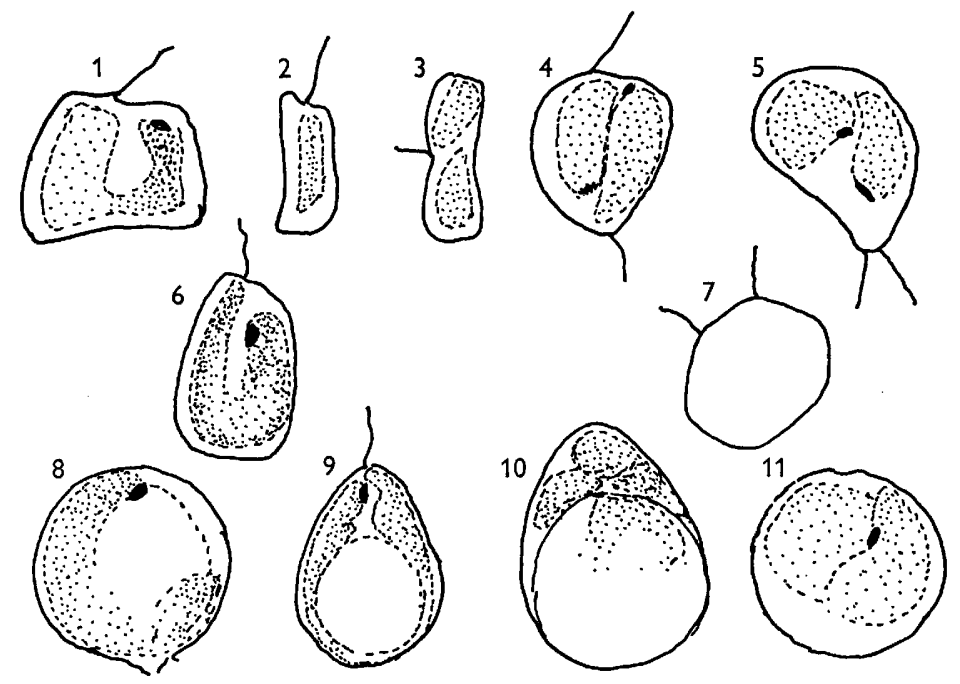

Fig. 1. 1-3: three views of organisms; 1, broad view; 2, edgewise, anterior/posterior axis; 3, edgewise, transverse axis. 4, organism with two flagella at opposite poles; 5 , organism with two flagella close together; 6, trapezoid organism longer than broad; 7 , outline of organism with two flagella somewhat separated; 8, spherical organism with large leucosyn body. 9-11, Stages in cyst formation: 9, large leucosyn body seen at rear of cell; 10, protoplast passing into cyst wall within cell membrane; 11, fully formed cyst. All $\times \mathbf{2 0 0 0}$.

The cyst is spherical to broadly oval, with an anterior pore. It appears to have a punctate wall but this appearance may be due to the presence of the punctate mother cell wall enclosing the cyst. Cysts were seen in large numbers in isolated organisms and among agglomerates of non-motile organisms embedded in mucilage.

Typical dimensions. The organisms anterior to posterior pole measured 6-6.5 $\mu$; lateral measurements 3-4 $\mu$, and 6-9 $\mu$. Cyst 7-9 $\mu$ diameter, or when oval $9-9 \cdot 5 \times 7-8 \mu$.

Comparison. This description is in general agreement with the descriptions given by Skuja (1939) and Bourrelly (1957). Skuja's measurements 10-12 $\times 7-10 \times 2-3 \mu$ show a slightly more flattened organism, elongated in the anterior-posterior direction; Bourrelly's measurements, $5 \times 5 \times \mathbf{2 - 2 \cdot 5} \mu$, show a smaller organism. These differences may denote different strains, different environmental conditions or different stages in the life cycle but are not, in my view, sufficient to constitute different species. Both Skuja and Bourrelly described two chromatophores, I 
observed only one; this might be a difference of interpretation. Like many members of the Chrysophyceae the Sphaleromantis tetragona chromatophore has two strongly marked lobes which are joined by a narrow and somewhat obscure basal bridge. I agree with Bourrelly's statement that the organism appears to have a rigid membrane.

Developmental stages. When I first examined Sphaleromantis tetragona, organisms like those already described were present in very large numbers and any other forms which may have been present were not studied. A few days later another sample was looked at, many organisms were seen to have two flagella and in some of these organisms two red eye spots were clearly visible (Fig. 1; 4, 5, 7). The flagella were sometimes close together or only slightly apart, and sometimes at opposite poles. The organism had lost its characteristic flattened shape and had become ovoid or nearly so. In some organisms (Fig. 1; 4, 5) two chromatophores were clearly visible and neither was $U$-shaped. At this time it was assumed that these organisms were dividing, a process which $I$ have watched in Mallomonas and in Synura, but unfortunately I did not watch the process on this occasion. Since reading the paper on conjugation in Mallomonas fastigiata var. Kriegerii by Wawrik (1960) I realize that what I describe above might be a stage in conjugation and not of division.

Electron microscopy. The rather rigid appearance of Sphaleromantis tetragona implies some sort of sheath or cell wall. No sheath can be distinguished with the optical microscope but with the electron microscope a very elaborate sheath is seen. This sheath covers the whole cell, including the flagellum. It may fit closely round the protoplasm ( $\mathrm{Pl} .2$, fig. 5) or be separated from it (Pl. 1, fig. 3). The appearance of the sheath is best seen in replicas (Pl. 1, figs. 1, 2, 4). This sheath is a membrane ornamented with closely-set raised rings and scattered hairs which bear four terminal branches (which I call 'dendroid hairs') and also crimped or twisted threads. All of these seem to be built up of the same material, which has a dark line, either a ridge or an indentation, running along it. The flagellum sheath is best understood by comparing the replica shown in Pl. 1, fig. 1 with the more highly magnified direct electron micrograph shown in Pl. 2, fig. 6. These micrographs were all made from fixed material which was, of course, subsequently dried so that some flattening and distortion may have occurred. The flagellum (Pl. 2, fig. 6) shows a dark core presumably the $2+9$ fibrils, and around this is the sheath. The sheath shows the usual rings and numerous dendroid hairs, here seen on two sides only, possibly because of flattening. In addition the flimmer are seen on both sides of the flagellum but I could not see their connexion with the core. The flimmer are unlike those of other Chrysophyte which I know, in that they point in different directions and often stick together in groups of from two to five or even more. The groups may divide and further out reunite or form fresh groups, but the individual flimmer threads can be traced through these groups. A certain amount of mucilage is present over the organism and in other parts of the background and this may have contributed to the unusual appearance by causing artifacts as the preparation dried.

Composition of the sheath. The rings, dendroid hairs and crimped threads appear to be made of organic substance, tough and possibly horny in texture. That they are not made of calcium carbonate was shown by treating some fixed material with acetic acid before preparing a replica; this treatment had no influence on the 
appearance of the replica. Likewise the absence of silica is shown by treatment with hydrofluoric acid, which did not influence the appearance of the replica; compare Pl. 1, fig. 1 (prepared with hydrofluoric acid treatment) with Pl. 1, fig. 2 (untreated with hydrofluoric acid). The material did, however, dissolve in chromic + sulphuric acid mixture while associated silica scales were unaltered. Strong chromic + sulphuric acid dissolved the Sphaleromantis organisms, leaving no trace. Dilute chromic + sulphuric acid left some residue of a fixed dried microscopical preparation and a replica was made from this. At magnification $\times 3,000$ nothing intelligible could be seen either of the form of the organism or of the sheath structure; but at magnification $\times 32,000$, numbers of rings could be seen, mostly much corroded, though a few for some reason were only slightly affected, and the dendroid hairs and crimped threads had vanished.

I wish to thank Professor R. W. Ditchburn, F.R.S. and Dr T. Evans for allowing me to use the electron microscope in J. J. Thomson Physical Laboratory, University of Reading, and Mr G. Wood for making most of the preparations illustrated here and giving me technical help.

\section{REFERENCES}

Bourrelly, P. (1957). Recherches sur les Chrysophycées. Rev. algol. Ser. 1, 250.

Harris, K. \& Bradley, D. E. (1958). Some unusual Chrysophyceae studied in the electron microscope. J. gen. Microbiol. 18, 72.

Pascher, A. (1910). Chrysomonaden aus dem Hirschberger Grossteiche. Monogr. Int. Rev. Hydrobiol. Hydrogr. $I$.

Skuja, H. (1939). Beitrag zur Algenflora Lettlands, II. Acta Hort. bot. Univ. latv. 11.

Wawrik, F. (1960). Sexualität bei Mallomonas fastigiata var. Kriegerii. Arch. Protistenk. 104, 541 .

\section{EXPLANATION OF PLATES}

Sphaleromantis tetragona

Plate 1

Fig. 1. Replica of an organism with flagellum; $\times 8000$.

Fig. 2. Replica of part of the sheath of the organism; $\times 32,000$.

Fig. 3. Direct electron micrograph of an organism showing a loose sheath with its flagellum; $\times 12,000$.

Fig. 4. Part of the sheath showing one dendroid hair and several rings; $\times 64,000$.

Plate 2

Fig. 5. Direct electron micrograph of an organism showing a closely fitting sheath with its flagellum; $\times \mathbf{1 2 , 0 0 0 \text { . }}$

Fig. 6. Direct electron micrograph of a flagellum. The two ovals are scales of a different organism $\times \mathbf{2 6 , 0 0 0}$. 

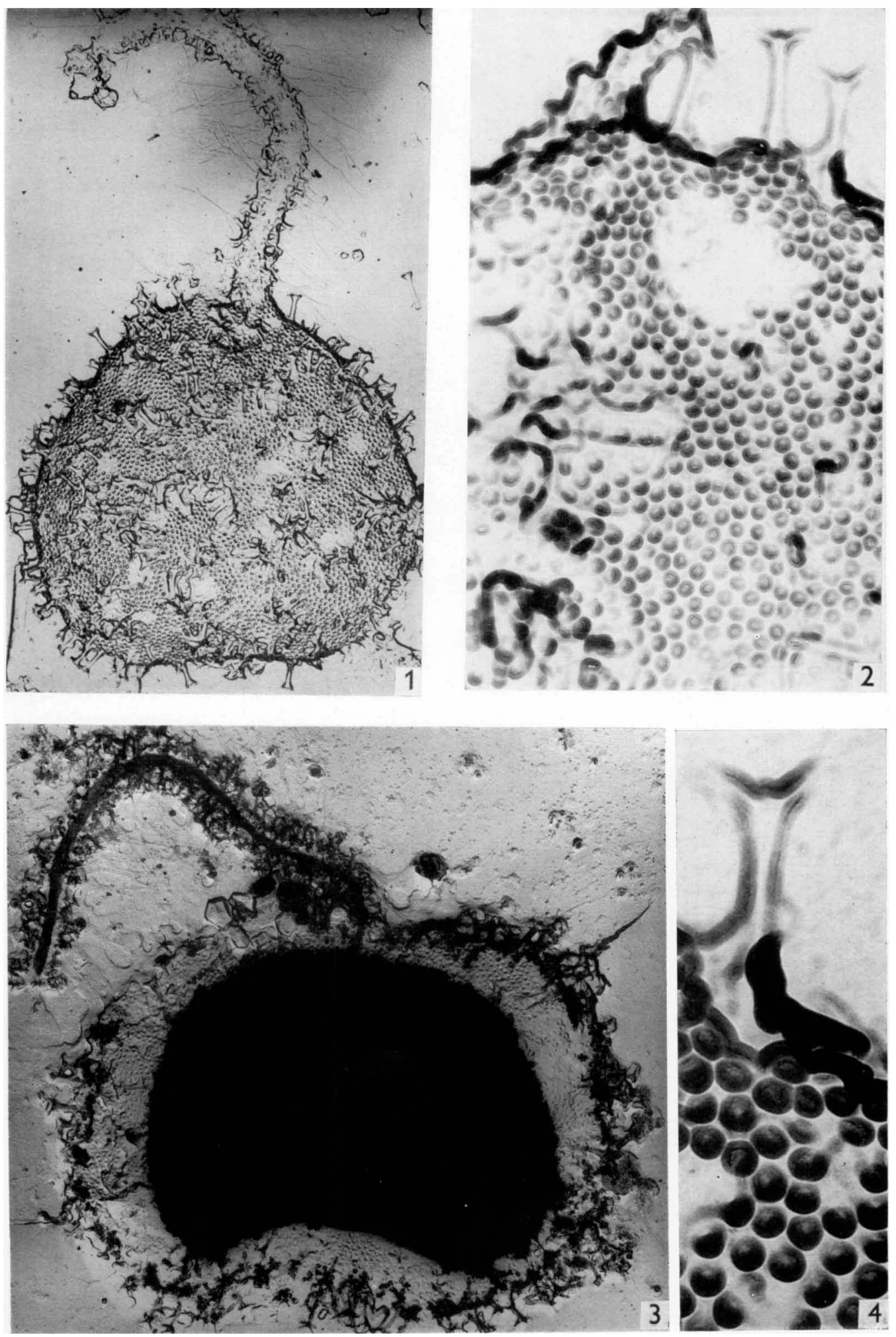
Journal of General Microbiology, Vol. 33, No. 2

Plate 2
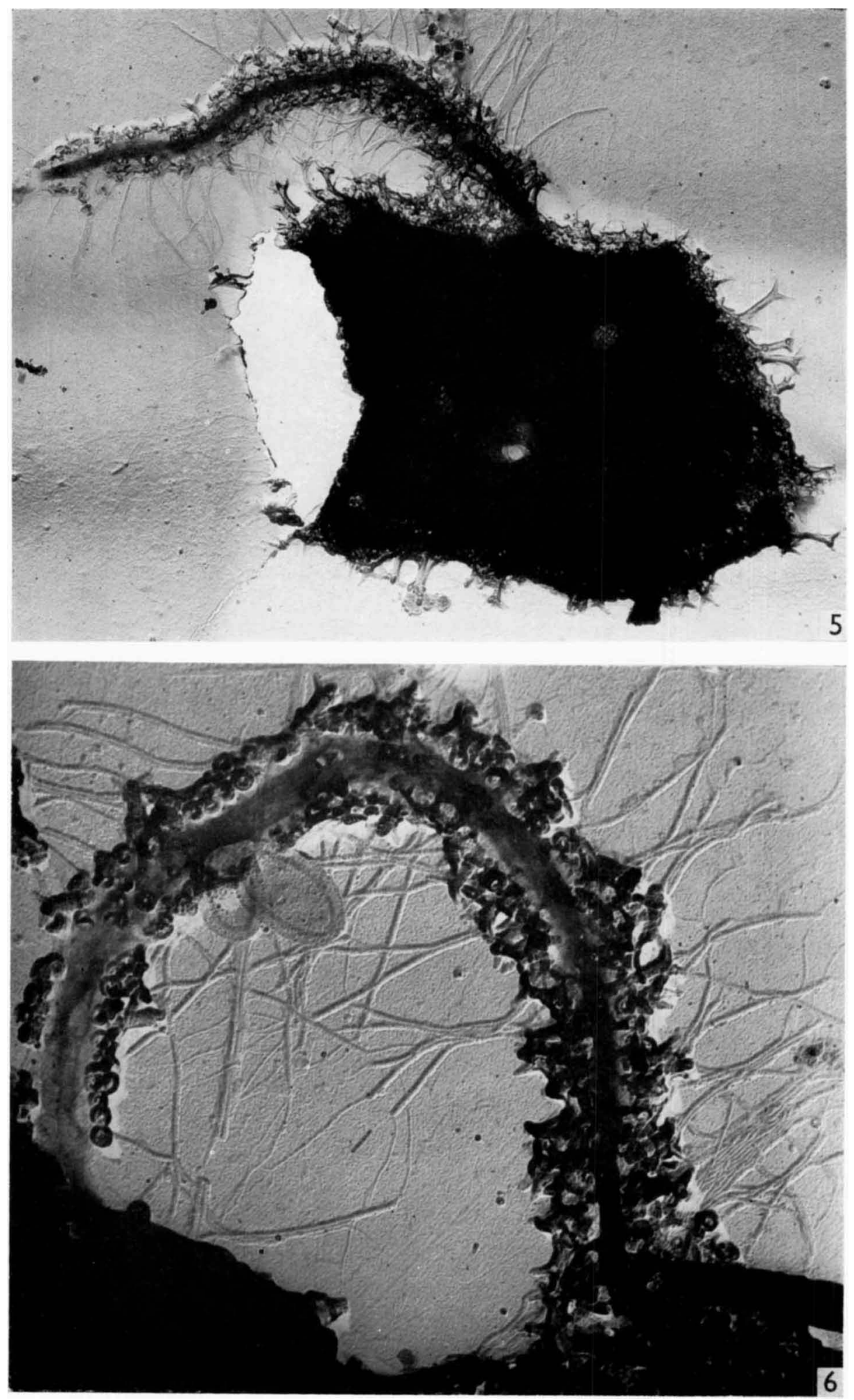